\title{
Uterine myomatosis and portal vein thrombosis: a rare association
}

\section{Elamurugan Sujindra*, Sai Chandran Sabita, Arounassalame Bupathy}

Department of Obstetrics and Gynecology, Indira Gandhi Medical College and Research Institute, Puducherry, India

Received: 23 July 2016

Accepted: 16 August 2016

\section{*Correspondence:}

Dr. Sujindra Elamurugan,

E-mail: sujindra@rediffmail.com

Copyright: (C) the author(s), publisher and licensee Medip Academy. This is an open-access article distributed under the terms of the Creative Commons Attribution Non-Commercial License, which permits unrestricted non-commercial use, distribution, and reproduction in any medium, provided the original work is properly cited.

\begin{abstract}
Uterine leiomyomas are the most common pelvic tumors in women and occur in 20-30\% of women over 30 years of age. Many complications are seen with fibroid. We report a rare case of a large uterine leiomyoma associated with portal vein thrombosis. 50-year patient presented lower abdomen swelling associated with pain and breathlessness, diagnosed as multiple fibroids. She had massive splenomegaly. Abdomen Doppler revealed splenomegaly with thrombosis of portal, splenic and superior mesenteric vein. Total abdominal hysterectomy with bilateral salpingooophorectomy was done. Iron deficiency anaemia with thrombocytosis caused by fibroid was the identified cause for portal vein thrombosis.
\end{abstract}

Keywords: Uterine myomatosis, Portal vein, Thrombosis, Iron deficiency anaemia

\section{INTRODUCTION}

Uterine leiomyomas are the most common pelvic tumors in women and occur in $20-30 \%$ of women over 30 years of age. ${ }^{1}$ Many complications are seen with fibroid. Those to be mentioned are torsion of a subserosal pedunculated leiomyoma, urinary retention, hemorrhage and thromboembolism. Thrombosis and subsequent embolic phenomenon due to large uterine fibroids is a very rare complication. Literature has quoted case reports were pelvic vein thrombosis has been encountered in patients with large uterine fibroids. ${ }^{2-7}$ Various causes and pathogenesis have been discussed as the contributing factors for development of thrombosis in the pelvic veins. But there has been no such report of an association of uterine fibroid with portal vein thrombosis. We present a rare case of a large uterine leiomyoma associated with portal vein thrombosis. Consent has been obtained from the patient to publish the details in a case report.

\section{CASE REPORT}

A 50-year-old female patient presented to the gynaecology OPD with complaints of Swelling and pain in the lower abdomen for past 5 months and amenorrhea for 2 months. Swelling was gradually increasing in size and was associated with pain radiating to the back and loin. It was also associated with breathlessness, loss of appetite and loss of weight. On physical examination, she was thin built with a body mass index of $19.5 \mathrm{~kg} / \mathrm{m}^{2}$, body temperature $37^{\circ} \mathrm{C}$, blood pressure $100 / 70 \mathrm{mmHg}$, heart rate 84 beats per min and respiratory rate of 24 breaths per min with clear lung sounds. Examination of the abdomen revealed a mass around 26 weeks size of gravid uterus, irregularly enlarged and non-tender. The largest myoma was $8 \times 8 \mathrm{~cm}$. Multiple subserous fibroids were palpated, each measuring 4-5 $\mathrm{cm}$. Apart from the fibroid she also had dilated veins in the flanks and massive splenomegaly which was palpated $6 \mathrm{~cm}$ below the costal margin. So an initial working diagnosis of uterine myomatosis with splenomegaly was made and was planned to evaluate for the causes of splenomegaly before further intervention.

Hematologic testing revealed hemoglobin of $8.9 \mathrm{~g} / \mathrm{dL}$,

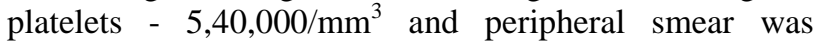
microcytic hypochromic anaemia with thrombocytosis. Coagulation profile was unremarkable with a prothrombin time INR of 1.5. Renal function (Blood urea - $25 \mathrm{mg} / \mathrm{dl}$, Serum creatinine - $0.9 \mathrm{mg} / \mathrm{dl}$ ) and liver 
function (T. Bilirubin $0.8 \mathrm{mg} / \mathrm{dl}$, T. Protein- $6.8 \mathrm{mg} / \mathrm{dl}$, AST-37 IU/ml, AST-63 IU/ml , ALP-118 IU/ml) parameters were normal. Chest radiograph and electrocardiogram reports were normal. An ultrasound abdomen showed enlarged spleen, $16.2 \mathrm{~cm}$ with thrombosis of splenic vein. Portal vein was $12 \mathrm{~mm}$ and echogenic with no flow. Liver and bilateral kidneys were normal. Uterus was enlarged in size with multiple intramural, subserous and cervical fibroid; largest measuring $13 \times 9 \times 9 \mathrm{~cm}$. Upper gastro-intestinal endoscopy should grade I-II oesophageal varies with pan gastritis. Abdomen Doppler revealed splenomegaly with thrombosis of portal, splenic and superior mesenteric vein with cavernous flow, multiple collaterals of splenic hilum and splenic renal axis and dilated and tortuous left renal vein. The final diagnosis was uterine myomatosis with extra-hepatic portal vein obstruction and splenomegaly.

Total abdominal hysterectomy with bilateral salpingooophorectomy was done. Intra-operatively the uterus was replaced by multiple fibroids around 15 in number and the uterine specimen weighed $1.5 \mathrm{~kg}$, bilateral ovaries were normal. Intra-operative and post-operative period was uneventful with within normal blood loss. At postoperative follow up after 4 weeks she was comfortable. The dilated flank veins had disappeared and splenomegaly had reduced to $4 \mathrm{~cm}$ below costal margin. However Doppler still showed thrombosis of splenic and portal vein. She was advised follow up after three months.

\section{DISCUSSION}

Uterine leiomyoma, or fibroid as it is commonly called, are benign tumors that originate in the uterus. They are the most common benign pelvic tumor in women of the reproductive age group and constitute one the major causes of abnormal uterine bleeding in the patients. ${ }^{1}$ Most fibroids don't cause symptoms only 10 to 20 percent of women who have fibroids are symptomatic and require treatment. Clinical manifestations of uterine fibroids depend on their size, location within the uterus, and how close they are to adjacent pelvic organs. These are most commonly symptoms of abnormal bleeding, pain and pressure. Venous thrombosis due to large uterine fibroids is a very rare complication. ${ }^{3-6}$

Various studies have reported deep vein thrombosis of the pelvic and femoral veins in association with uterine fibromyoma. ${ }^{6-8}$ In women presenting with acute pulmonary thromboembolism, the possibility of uterine leiomyoma causing deep vein thrombosis of the pelvic vessels should be considered. Deep vein thrombosis of the lower extremities leading to acute pulmonary thromboembolism has also been reported. ${ }^{9}$ Mesenteric vein thrombosis secondary to compression by a large fibroid can cause acute abdomen. ${ }^{10}$ Ours is the first study to report uterine myomatosis in association with thrombosis of the portal system.
Why do we report this as a rare association of fibroid? Here we will have to answer two questions. One, if fibroid is the reason behind the thrombosis in the portal system, what is the mechanism behind it? Two, why isn't the portal system thrombosis (extra-hepatic portal vein obstruction) a co-incidental finding rather than an association of fibroid?

The authors have made an attempt to answer the above two questions. Thrombus formation is governed by the principles of the Virchow's triad namely, hemostasis, endothelial injury and hypercoagulability. When considering the mechanism in large fibroid uterus, it is attributed to stasis of blood in pelvic veins due to obstruction. What is the attributable cause in our patient? It has been reported that iron deficiency anaemia is associated with thrombosis of cerebral veins and venous sinuses. Our patient had iron deficiency anaemia with thrombocytosis. This is one main attributable cause. Iron acts as a controller of thrombopoisis and regulates the level of platelets. ${ }^{11}$ In iron deficiency the level of megakaryocytes increase thereby increasing the platelet level, thus resulting in a hypercoagulable state. ${ }^{12}$ Sometimes even thrombocytopenia can be present due to over consumption of platelets. Iron deficiency also induces a hypercoagulable state by altering pattern of blood flow. The microcytosis resulting from iron deficiency causes reduced red cell deformability and increased viscosity, which contributes to thrombosis in a negative-pressure environment, as is found in veins. ${ }^{13}$ Further poor oxygenation due to reduced hemoglobin levels lead to metabolic stress and endothelial damage. ${ }^{14}$

The portal vein forms at the junction of the splenic vein and the superior mesenteric vein behind the pancreatic head. Thrombosis of the portal vein can occur due to hepatic causes like cirrhosis or malignancies or extra hepatic causes. In our patient it was extra hepatic portal vein obstruction. Extrinsic obstructions and inherited hypercoagulable states have been ruled out in our patient (normal ultrasound and coagulation study). Further reduction in the size of splenomegaly after removal of fibroid also suggests an association between them. Hence we conclude that this appears to be a de-novo presentation of portal vein thrombosis associated with uterine myomatosis due to the presence of iron deficiency anaemia with thrombocytosis.

As this the first reported case we have tried to draw an association between fibroid uterus and portal vein thrombosis. Meticulous search to look for such complications in future can further enlighten us for the betterment of health care services to patients.

\section{CONCLUSION}

Venous thrombosis in patients with fibroid though a rare complication has now been reported in many cases. So importance should be given to search for such 
complications, especially in patients with large fibroids in atypical sites also.

Funding: No funding sources

Conflict of interest: None declared

Ethical approval: Not required

\section{REFERENCES}

1. Evans P, Brunsell S. Uterine fibroid tumors: diagnosis and treatment. Am Fam Physician. 2007;75:1503-8.

2. Stanko CM, Severson II MA, Molpus KL. Deep venous thrombosis associated with large leiomyomata uteri: a case report. J Reprod Med. 2001;46:405-7.

3. Falcone M, Serra P. Massive pulmonary embolism in a woman with leiomyomatous uterus causing pelvic deep venous thrombosis. Annali Italiani di Medicina Interna. 2005;20:104-7.

4. Hawes J, Lohr J, Blum B, Bhati A, Bhaskaran J, Engel A. Large uterine fibroids causing mechanical obstruction of the inferior vena cava and subsequent thrombosis: a case report. Vasc Endovascular Surg. 2006;40:425-7.

5. Bonito M, Gulem L, Basili R, Brunetti G, Roselli D. Thrombosis associated with a large uterine myoma: case report. Clin Exp Obstet Gynecol. 2007;34:1889.

6. Khilanani R, Dandolu V. Extensive iliac vein thrombosis as a rare complication of a uterine leiomyoma: a case report. J Reprod Med. 2007;52:537-8.

7. Srettabunjong S. Systemic thromboembolism after deep vein thrombosis caused by uterine myomas. Am J Forensic Med Pathol. 2013;34:207-9.

8. Ippolito E, Buora A, Belcaro G, Alari G, Arpaia G, Ciammaichella G. Deep Vein Thrombosis and Pulmonary Embolism in a Patient Affected by Uterine Fibroids: Clinical Case. Panminerva Medica. 2012;54:97-9.

9. Nawaz R, Haque S, Shaha K. Deep Vein Thrombosis and Pulmonary Embolism in a Woman with Uterine Myoma. Bangladesh J Obstet Gynaecol. 2008;23:7881.

10. Sheikh HH. Uterine Leiomyoma as a Rare Cause of Acute Abdomen and Intestinal Gangrene. Am J Obstet Gynecol. 1998;179:830-1.

11. Beguin Y. Erythropoietin and platelet production. Haematologica. 1999;84:541-7.

12. Karpatkin S, Garg SK, Freedman ML. Role of iron as a regulator of thrombopoiesis. Am J Med. 1974;57:521-5.

13. Hartfield DS, Lowry NJ, Keene DL, Yager JY. Iron deficiency: a cause of stroke in infants and children. Pediatr Neurol. 1997;16:50-3.

14. Balci K, Utku U, Asil T, Büyükkoyuncu N. Deep cerebral vein thrombosis associated with iron deficiency anemia in adults. $\mathbf{J}$ Clin Neurosci. 2007;14:181-4.

Cite this article as: Sujindra E, Sabita SC, Bupathy A. Uterine myomatosis and portal vein thrombosis: a rare association. Int J Reprod Contracept Obstet Gynecol 2016;5:3265-7. 